\title{
Kecerdasan Emosi dengan Resiliensi Berdasarkan Jenis Kelamin pada Remaja di Panti Asuhan
}

\author{
Pujining Wanodya Nyiagani ${ }^{1}$, Wahyuni Kristinawati ${ }^{2}$ \\ 1,2Fakultas Psikologi, Universitas Kristen Satya Wacana, Jl. Diponegoro 52-60 Salatiga, Jawa \\ Tengah, Indonesia 50711 \\ 1wnyiagani@gmail.com, ㄹwahyuni.kristinawati@uksw.edu
}

Article History:

Received

2021-11-13

Review

2021-12-11

Revised

2021-12-15

Accepted

2021-12-16

Published

2021-12-28
Abstract. This study aims to find out the correlation between emotional intelligence and resilience in terms of gender among adolescents who live in social shelters. This research uses a quantitative approach with a correlational and comparative design. The sample 55 adolescents selected by purposive sampling technique in Karanganyar Regency. The criteria for respondents are 12-21 years and live in social shelters for more than 1 year. The measuring instrument used resilience scale by Connor and Davidson (2003) and the scale of emotional intelligence by Schutte, Malouff, Hall, Hagegerty, Cooper, Golden, dan Domheim (1998). The data analysis using pearson product moment correlation test and t-test. The results showed: first, there is a positive correlation between emotional intelligence and resilience of adolescents in social shelters with (r) 0,552 that had a significance $0,000(p<0,05)$. Second, there is a positive correlation between emotional intelligence and resilience of male adolescents with (r) 0,640 that had a significance 0,003 $(p<0,05)$ and female adolescents with (r) 0,516 that had a significance $0,001(p<0,05)$. Third, there is no significant difference between male and female adolescents in social shelters, both emotional intelligence $(p=0,149 ; p>0,05)$ and resilience $(p=0,917$; $p>0,05)$. Fourth, the resilience scores and emotional intelligence of adolescents in social shelters, are in the medium category.

Keywords: resilience, emotional intelligence, gender, adolescents, social shelters

Abstrak. Penelitian ini bertujuan untuk mengetahui hubungan antara kecerdasan emosi dengan resiliensi ditinjau dari jenis kelamin pada remaja yang tinggal di panti asuhan. Penelitian ini menggunakan pendekatan kuantitatif dengan desain korelasional dan komparatif. Sampel penelitian yaitu 55 remaja yang tinggal di panti asuhan yang dipilih dengan teknik purposive sampling di Kabupaten Karanganyar. Kriteria responden yaitu remaja berusia 1221 tahun dan tinggal di panti asuhan selama lebih dari 1 tahun. Alat ukur menggunakan skala resiliensi dari Connor dan Davidson (2003) dan skala kecerdasan emosi dari Schutte, Malouff, Hall, Hagegerty, Cooper, Golden, dan Domheim (1998). Analisis data menggunakan uji korelasi product moment pearson dan t-test. Hasil penelitian menunjukkan bahwa: pertama, ada hubungan positif antara kecerdasan emosi dengan resiliensi pada remaja yang tinggal di panti asuhan dengan (r) sebesar 0,552 memiliki signifikansi 0,000 $(p<0,05)$. Kedua, ada hubungan positif antara kecerdasan emosi 
dengan resiliensi remaja laki-laki dengan ( $\mathrm{r}$ ) sebesar 0,640 memiliki signifikansi 0,003 $(\mathrm{p}<0,05)$ dan remaja perempuan dengan $(r)$ sebesar 0,516 memiliki signifikansi 0,001 $(\mathrm{p}<0,05)$. Ketiga, tidak terdapat perbedaan antara remaja laki-laki dan perempuan panti asuhan dalam hal kecerdasan emosi dengan ( $p=0,149 ; p>0,05)$ maupun resiliensi $(p=0,917 ; p>0,05)$. Keempat, skor resiliensi dan kecerdasan emosi remaja yang tinggal di panti asuhan berkategori sedang.

Kata kunci: resiliensi, kecerdasan emosi, jenis kelamin, remaja, panti asuhan

\section{Pendahuluan}

Salah satu periode dalam rentang kehidupan manusia adalah masa remaja, yaitu dari usia 12-21 tahun (Papalia, Old, \& Feldman, 2008). Masa remaja rawan terjadi konflik dengan diri sendiri maupun lingkungan sekitarnya karena masa remaja adalah periode seseorang mengalami masa transisi, baik fisik, emosional maupun sosial dari masa anakanak ke dewasa, sehingga periode ini menjadi periode yang penting dan kritis dalam kehidupan manusia. Oleh karena itu, remaja memerlukan peran keluarga terutama orang tua untuk siap menjalani tugas perkembangannya dengan baik, namun tidak semua anak dapat memiliki kehidupan bersama dengan keluarga untuk mendampingi di setiap perkembangannya. Menurut Apriani dan Listiyandini (2019) perpisahan anak dari keluarga disebabkan oleh faktor ekonomi yang rendah, perceraian, menjadi yatim dan/atau piatu. Kondisi seperti ini yang membuat anak harus tinggal di sebuah lembaga seperti panti asuhan supaya tetap mendapatkan kelayakan hidup.

Anak-anak yang tinggal di panti asuhan dituntut untuk dapat bersosialisasi dengan seluruh penghuni panti yang memiliki perbedaan latar belakang. Hal ini menimbulkan penilaian masing-masing remaja dan dapat memicu terjadinya konflik. Sebagian besar remaja yang tinggal di panti asuhan belum cukup menerima perhatian dari pengasuh karena jumlah pengaruh lebih sedikit dibanding jumlah remaja yang diasuh, sehingga kualitas perhatian yang diberikan sangat minim dan membuat remaja rentan mengalami tekanan psikologis (Sandri, 2015). Adapun kenyataan yang ditemukan oleh Harjanti (2021) pada beberapa panti asuhan di Karanganyar memiliki permasalahan yang sama yaitu dimana kondisi sosial dan fisik dari beberapa remaja di panti asuhan mengalami kurangnya privasi dan tidak aman karena banyaknya penghuni di panti asuhan. Mustafa dan Hadiyati (2019) menemukan bahwa remaja laki-laki panti asuhan memiliki permasalahan yaitu perkelahian dengan teman, sulit diatur dan diberi nasihat, sedangkan 
remaja perempuan ketika mempunyai permasalahan mereka cenderung memendam masalah dan menghindari masalah. Remaja yang tinggal di panti asuhan, rentan mengalami berbagai macam tekanan dan permasalahan daripada remaja yang masih tinggal bersama dengan keluarga (Rahmawati, Listiyandini, \& Rahmatika, 2019). Permasalahan dapat berdampak negatif terhadap perkembangan mental emosional apabila tidak dapat diselesaikan dengan baik (Albaroroh, 2016). Ketahanan dibutuhkan untuk menghadapi tantangan hidup ke depan dengan kondisi latar belakang yang kurang beruntung, agar kerentanan dalam menghadapi masalah tidak menimbulkan perilaku malasuai. Remaja membutuhkan resiliensi untuk membantu mereka bangkit dalam menghadapi kenyataan yang tidak diinginkan, sehingga dapat menjalani kehidupan dengan lebih produktif.

Menurut Connor dan Davidson (2003) resiliensi adalah wujud dari kualitas pribadi yang memungkinkan seseorang dapat berkembang dalam menghadapi situasi sulit. Terdapat lima aspek pada resiliensi yaitu kompetensi personal, standar yang tinggi, dan keuletan; percaya pada diri sendiri, memiliki toleransi terhadap afek negatif, dan kuat menghadapi stres; penerimaan positif terhadap perubahan dan menjalin hubungan baik dengan orang lain; kontrol diri; pengaruh spiritual.

Faktor yang mempengaruhi resiliensi adalah jenis kelamin, usia, ras, pendidikan, tingkat trauma, pendapatan, dukungan sosial, frekuensi penyakit kronis, tekanan kehidupan masa lalu dan sekarang (Bonano, Galea, Bucciarelli \& Vlahol, 2007). Perkembangan masalah mental dapat dipengaruhi oleh jenis kelamin, remaja perempuan cenderung lebih menunjukkan gejala permasalahan mental daripada remaja laki-laki (Haryanti, Pamela, \& Susanti, 2016). Mahardika (2017) mengatakan bahwa laki-laki digambarkan memiliki sifat agresif dan kompetitif, sedangkan perempuan digambarkan memiliki sifat menerima dan empati, sehingga kedua jenis kelamin tersebut juga akan berbeda dalam menanggapi tuntutan dari tekanan sosial. Penelitian yang dilakukan oleh Erdogan, Ozdogan, dan Erdogan (2015) menyatakan bahwa pada usia 19-22 tahun, lakilaki menunjukkan tingkat resiliensi yang lebih tinggi daripada perempuan. Berbeda dengan temuan Sunarti, Islamia, Rochimah, dan Ulfa (2018) yang menunjukkan bahwa tidak terdapat perbedaan antara resiliensi yang dimiliki remaja laki-laki dan remaja perempuan yang berusia 15-18 tahun.

Apriani dan Listiyandini (2019) mengatakan bahwa terdapat salah satu aspek resiliensi psikologis yang dapat mengembangkan resiliensi psikologis pada individu yakni 
penerimaan positif terhadap perubahan, maka dibutuhkan kemampuan untuk memahami, mengendalikan emosi diri maupun orang lain, dan berpikir kreatif. Kemampuan tersebut berkaitan dengan kecerdasan emosional. Kecerdasan emosional menurut Mayer, Salovey, Carus, dan Sitarenios (2003) adalah kemampuan untuk memahami perasaan dan emosi diri sendiri maupun orang lain, mengidentifikasi perbedaan emosi yang dirasakan, serta memanfaatkan informasi yang berkaitan dengan emosi sebagai pola untuk mengelola dan memikirkan keputusan sebelum bertindak. Empat aspek kecerdasan emosi yaitu persepsi emosi, memfasilitasi pemikiran menggunakan emosi, pemahaman emosi, pengaturan emosi.

Menerapkan kecerdasan emosional akan berdampak positif pada berbagai bidang kehidupan seperti relasi interpersonal, akademik, kesehatan fisik, serta resiliensi psikologis (Seligman dalam Setyowati, Hartati, \& Sawitri 2010). Resiliensi sebagai kemampuan untuk beradaptasi dalam kesulitan atau tekanan yang mampu mengembalikan keadaan semula, maka kemampuan tersebut juga mencakup kompetensi personal dalam diri individu. Penelitian yang dilakukan oleh Fauziya dan Daulima (2017) mengungkapkan bahwa adanya hubungan yang signifikan antara kecerdasan emosi dengan resiliensi pada penyintas banjir usia 19-64 tahun. Hal tersebut didukung oleh penelitian Apriani dan Listiyandini (2019) yang menyatakan bahwa kecerdasan emosional menjadi faktor yang penting dalam peningkatan resiliensi psikologis pada remaja panti asuhan usia 11-18 tahun.

Goleman (2009) menyebutkan bahwa faktor yang mempengaruhi kecerdasan emosi yaitu pengalaman, usia, jenis kelamin, serta jabatan. Jenis kelamin berpengaruh pada perbedaan hormonal laki-laki dan perempuan, selain itu peran dan tuntutan sosial akan mempengaruhi perbedaan karakteristik emosi remaja laki-laki dan perempuan (Safari, 2019). Kecenderungan sifat yang dimiliki perempuan adalah empati, keibuan, lebih sensitif terhadap lingkungan, dan lebih menggunakan perasaan dalam berperilaku, serta mampu mengenali dan mengelola emosi dibandingkan laki-laki sehingga kecerdasan emosional perempuan lebih tinggi (Chong, Mahamod, \& Yamat, 2016; Meyers \& Loken, 2015). Hal ini berbeda dengan penelitian Safari dan Hestaliana (2019) yang membuktikan bahwa kecerdasan emosional perempuan lebih rendah dibandingkan laki-laki. Hasil penelitian tersebut mendukung penelitian Bariyyah dan Latifah (2019).

Penelitian Fauziya dan Daulima (2017) dan Apriani dan Listiyandini (2019) menyatakan bahwa ada hubungan antara resiliensi dan kecerdasan emosi, namun tidak 
meneliti lebih lanjut terkait dengan jenis kelamin. Berdasarkan latar belakang ini peneliti merasa perlu untuk melakukan penelitian apakah terdapat hubungan antara kecerdasan emosi dengan resiliensi ditinjau dari jenis kelamin pada remaja yang tinggal di Panti Asuhan dengan mengajukan hipotesis adanya hubungan positif antara kecerdasan emosi dengan resiliensi ditinjau dari jenis kelamin pada remaja yang tinggal di panti asuhan.

\section{Metode}

Penelitian ini menggunakan metode kuantitatif dengan desain penelitian korelasional dan komparatif. Penelitian ini menggunakan kecerdasan emosi sebagai variabel bebas $(\mathrm{X})$ sedangkan resiliensi sebagai variabel terikat $(\mathrm{Y})$. Teknik pengambilan sampel dalam penelitian ini yaitu menggunakan non-probability sampling dengan pendekatan purposive sampling. Responden penelitian adalah remaja berusia 12-21 tahun yang tinggal di panti asuhan lebih dari satu tahun di Kabupaten Karanganyar. Jumlah responden dalam penelitian ini yaitu 55 orang terdiri dari 36 perempuan dan 19 laki-laki. Variabel resiliensi diukur menggunakan The Connor-Davidson Resilience Scale (CD-RISC) yang disusun oleh Connor dan Davidson (2003), skala ini terdiri dari 25 item favorable. Uji reliabilitas menggunakan SPSS versi 25 skala resiliensi memperoleh 20 item yang valid dengan Alpha Cronbach sebesar 0,828. Variabel kecerdasan emosi diukur menggunakan alat ukur yang disusun oleh Schutte, Malouff, Hall, Hagegerty, Cooper, Golden, dan Domheim (1998) yang didasarkan oleh teori dari Mayer dan Salovey, skala ini terdiri dari 33 item. Hasil uji reliabilitas skala kecerdasan emosi dengan 22 item yang valid telah diperoleh hasil Alpha Cronbach sebesar 0,859. Skala resiliensi dan skala kecerdasan emosi yang digunakan dapat dikatakan reliabel dengan kriteria reliabilitas sangat tinggi karena $0,81<\mathrm{r} \leq 1,00$ (Arikunto, 2010).

\section{Hasil}

\section{Karakteristik Responden}

Responden pada penelitian ini merupakan 55 remaja yang tinggal di Panti Asuhan wilayah Kabupaten Karanganyar selama lebih dari satu tahun. Remaja laki-laki sebanyak 19 orang dan remaja perempuan sebanyak 36 orang dengan responden terbanyak berusia 16 tahun $(30,91 \%)$

\section{Analisis Deskriptif}

Berikut perhitungan nilai rata-rata, nilai minimal, nilai maksimal, dan standar deviasi skala resiliensi dan skala kecerdasan emosi. 
Philanthropy Journal of Psychology

Vol 5 Nomor 2 (2021), 295-305

ISSN 2580-6076 (Print), ISSN 2580-8532 (Online)

Tabel 1.

Kategorisasi Skor Resiliensi

\begin{tabular}{llllllll}
\hline \multirow{2}{*}{ Kategori } & \multirow{2}{*}{ Interval } & \multicolumn{4}{c}{ Frekuensi } & \multicolumn{3}{c}{ Persentase } \\
\cline { 3 - 8 } & & $\mathbf{P}$ & $\mathbf{P}$ & Total & L & P & Total \\
\hline Tinggi & $64 \leq \mathrm{X} \leq 76$ & 5 & 7 & 12 & $26 \%$ & $19 \%$ & $22 \%$ \\
Sedang & $51 \leq \mathrm{X} \leq 63$ & 8 & 19 & 27 & $42 \%$ & $53 \%$ & $49 \%$ \\
Rendah & $38 \leq \mathrm{X} \leq 50$ & 6 & 10 & 16 & $32 \%$ & $28 \%$ & $29 \%$ \\
Total & & $\mathbf{1 9}$ & $\mathbf{3 6}$ & $\mathbf{5 5}$ & $\mathbf{1 0 0 \%}$ & $\mathbf{1 0 0} \%$ & $\mathbf{1 0 0 \%}$ \\
Min = 38 & Max = 76 & SD $=\mathbf{9 , 5 5}$ & Mean $=\mathbf{5 5 , 6 5}$ & & \\
\hline
\end{tabular}

Keterangan: L: Laki-laki P: Perempuan

Pada tabel 1 diketahui bahwa variabel resiliensi menunjukkan skor minimum sebesar 38 sampai dengan skor maksimum sebesar 76, serta skor rata-rata 55,65 dengan standar deviasi 55,65. Berdasarkan tabel di atas diketahui bahwa sebagian besar dari 55 remaja yang tinggal di panti asuhan yaitu sejumlah 27 orang (49\%) baik laki-laki maupun perempuan memiliki resiliensi pada kategori sedang.

Tabel 2.

Kategorisasi Skor Kecerdasan Emosi

\begin{tabular}{llllllll}
\hline \multirow{2}{*}{ Kategori } & \multirow{2}{*}{ Interval } & \multicolumn{3}{c}{ Frekuensi } & \multicolumn{3}{c}{ Persentase } \\
\cline { 3 - 8 } & & L & $\mathbf{P}$ & Total & L & P & Total \\
\hline Tinggi & $67 \leq \mathrm{X} \leq 84$ & 6 & 12 & 18 & $32 \%$ & $33 \%$ & $33 \%$ \\
Sedang & $49 \leq \mathrm{X} \leq 66$ & 9 & 22 & 31 & $47 \%$ & $61 \%$ & $56 \%$ \\
Rendah & $30 \leq \mathrm{X} \leq 48$ & 4 & 2 & 6 & $21 \%$ & $6 \%$ & $11 \%$ \\
Total & & $\mathbf{1 9}$ & $\mathbf{3 6}$ & $\mathbf{5 5}$ & $\mathbf{1 0 0} \%$ & $\mathbf{1 0 0 \%}$ & $\mathbf{1 0 0 \%}$ \\
Min = 30 & Max = 84 & SD $=\mathbf{1 1}$ & Mean $=\mathbf{6 0 , 9 0}$ & & \\
\hline
\end{tabular}

Tabel 2 menunjukkan bahwa variabel kecerdasan emosi menunjukkan skor minimum sebesar 30 hingga skor maksimum sebesar 84, serta skor rata-rata 60,90 dengan standar deviasi 11. Berdasarkan tabel diatas diketahui bahwa sebagian besar dari 55 remaja panti asuhan yaitu sejumlah 31 orang (56\%) baik laki-laki maupun perempuan memiliki kecerdasan emosi pada kategori sedang.

Tabel 3.

Korelasi Kecerdasan Emosi Dengan Resiliensi

\begin{tabular}{llll}
\hline & & Kecerdasan Emosi \\
\hline Remaja Laki- & \multirow{2}{*}{ Resiliensi } & Pearson Correlation & 0,552 \\
laki dan & & Sig. (1-tailed) & 0,000 \\
Perempuan & & N & 55 \\
\hline \multirow{2}{*}{ Remaja Laki- } & \multirow{2}{*}{ Resiliensi } & Pearson Correlation & 0,640 \\
& & Sig. (2-tailed) & 0,003 \\
& & N & 19 \\
\hline \multirow{2}{*}{ Remaja } & \multirow{2}{*}{ Resiliensi } & Pearson Correlation & 0,516 \\
& & Sig. (2-tailed) & 0,001 \\
& & N & 36 \\
\hline
\end{tabular}


Analisis data korelasional menggunakan metode pearson product moment. Hasil uji korelasi pada tabel 3 menunjukkan bahwa koefisien korelasi antara variabel resiliensi dengan kecerdasan emosi adalah sebesar $r=0,552$ dengan nilai sig $=0,000(p<0,05)$. Pada tabel 4 menunjukkan remaja laki-laki memiliki korelasi (r) sebesar 0,640 dengan signifikansi $0,003(\mathrm{p}<0,005)$ dan pada tabel 5 menunjukkan remaja perempuan memiliki korelasi (r) sebesar 0,516 dengan signifikansi 0,001 $(\mathrm{p}<0,005)$. Hal ini membuktikan ada hubungan positif antara kecerdasan emosi dengan resiliensi, artinya semakin tinggi resiliensi maka semakin tinggi juga kecerdasan emosi yang dimiliki remaja yang tinggal di panti asuhan.

\section{Diskusi}

Penelitian ini menunjukkan tidak terdapat perbedaan resiliensi antara remaja lakilaki dan perempuan panti asuhan, sesuai dengan penelitian Hendrayu, Kinanthi, dan Brebahama (2017). Hasil ini bertolak belakang dengan penelitian Oktasari dan Wahyudin (2021) bahwa ada perbedaan resiliensi remaja laki-laki dan remaja perempuan, ditemukan remaja perempuan memiliki resiliensi lebih tinggi dibandingkan remaja lakilaki. Ballenger-Browning dan Johnson (2010) menjelaskan bahwa gender merupakan variabel yang inkonsisten dalam memprediksi resiliensi. Terbukti pada beberapa penelitian sebelumnya telah mengungkapkan hasil yang berbeda-beda.

Pada perhitungan Independent Sample T-Test menunjukkan nilai signifikansi untuk perbedaan kecerdasan emosi remaja laki-laki dan perempuan adalah 0,149 $(p>0,05)$ yang berarti kecerdasan emosi antara remaja laki-laki dan perempuan panti asuhan tidak ada perbedaan. Nilai rata-rata responden remaja laki-laki sebesar 57,95 dan remaja perempuan sebesar 62,47 . Pada sebagian besar responden (56\%) memiliki kecerdasan emosi pada kategori sedang. Hal ini berarti remaja yang tinggal di panti asuhan mampu memahami perasaan dan emosi diri sendiri maupun orang lain, mengidentifikasi perbedaan emosi yang dirasakan, serta memanfaatkan informasi yang berkaitan dengan emosi sebagai pola untuk mengelola dan memikirkan keputusan sebelum bertindak dalam lingkungan panti asuhan.

Kecerdasan emosi pada remaja laki-laki dan perempuan di penelitian ini juga tidak terdapat perbedaan, sejalan dengan penelitian Djafar (2018). Namun hasil penelitian ini tidak mendukung pendapat Goleman (2000) yang menyatakan bahwa terdapat perbedaan kecerdasan emosi pada remaja laki-laki dan perempuan. Ada dua alasan mengapa tidak 
terdapat perbedaan antara remaja laki-laki dan perempuan yaitu pertama, kedua jenis kelamin tersebut memiliki kebutuhan aktualisasi diri yang sama, maka mereka memiliki peluang yang sama untuk tumbuh dan berkembang, kedua yaitu tuntutan dan kondisi lingkungan remaja tinggal relatif sama, sehingga tuntutan tersebut akan berusaha mereka penuhi dengan berbagai cara yang sama (Aziz dalam Putri \& Yusri, 2021). Perbedaan kecerdasan emosi seseorang tidak hanya pada jenis kelamin saja (Shanta \& Gargiulo, 2014).

Resiliensi dan kecerdasan emosi pada penelitian ini menunjukkan tidak terdapat perbedaan antara remaja laki-laki dan perempuan, hanya terdapat sedikit perbedaan ratarata. Hal ini dapat disebabkan oleh responden penelitian ini didominasi oleh remaja usia 16 tahun dengan jumlah 17 orang baik laki-laki dan perempuan. Sari (dalam Yuniar \& Darmawati, 2017) mengatakan bahwa kematangan emosi pada usia tersebut tidak ada lagi yang rendah, baik laki-laki maupun perempuan. Dari beberapa responden laki-laki terlihat mengerjakan pekerjaan yang dilakukan oleh perempuan seperti menyiapkan minuman. Hal tersebut menjadi bukti bahwa perubahan peran gender dari tahun ke tahun semakin berubah, (Kail dalam Eliyawati \& Prasukma, 2013). Maka adanya perubahan peran gender dapat menjadi salah satu faktor bahwa tidak adanya perbedaan resiliensi remaja laki-laki dan perempuan. Sebagian besar remaja yang tinggal di panti asuhan baik laki-laki maupun perempuan sedang dalam menempuh pendidikan. Kesetaraan hak untuk mendapatkan pendidikan setinggi-tingginya antara laki-laki dan perempuan dapat mempengaruhi resiliensi remaja, karena ketika individu memiliki pengalaman menempuh pendidikan lebih tinggi maka akan memiliki perasaan dan ingatan yang lebih luas, fleksibel, dan terbuka mengenai banyak hal (Eliyawati \& Prasukma, 2013). Selain itu, sebanyak 55 responden tinggal di panti asuhan selama lebih dari satu tahun. Remaja yang tinggal di panti asuhan lebih dari satu tahun sudah mampu menyesuaikan diri baik secara sosial maupun terhadap berbagai sumber stress yang ada di lingkungan panti asuhan (Hartati dan Respati, 2012). Oleh karena itu mereka belajar bangkit dari kesulitan yang dihadapi dengan memanfaatkan hubungan mereka dengan orang lain.

Pada penelitian ini terdapat beberapa keterbatasan yaitu persebaran demografi tidak merata, responden perempuan lebih banyak dibandingkan responden laki-laki. Hal ini membuat analisis perbedaan resiliensi dan kecerdasan emosi ditinjau dari jenis kelamin tidak memungkinkan untuk dilakukan. Dalam penelitian ini unsur demografis yang dikaji dalam hubungan antar variabel adalah jenis kelamin, sementara berdasarkan 
rekomendasi Apriani dan Listiyandini (2019) faktor orang terdekat lebih berperan terhadap perbedaan variabel, sedangkan variabel lain seperti usia, pendidikan, dan alasan tinggal di panti asuhan tidak mempengaruhi tinggi rendahnya skor. Peneliti selanjutnya dapat mengeksplorasi lebih jauh faktor orang terdekat remaja yang tinggal di panti asuhan.

\section{Simpulan}

Berdasarkan hasil dan pembahasan di atas, maka dapat disimpulkan bahwa adanya hubungan positif antara kecerdasan emosi dengan resiliensi remaja laki-laki dan perempuan yang tinggal di panti asuhan. Arah hubungan yang terjadi berarti semakin tinggi kecerdasan emosi maka semakin tinggi resiliensi remaja yang tinggal di panti asuhan dan begitu pula sebaliknya. Resiliensi dan kecerdasan emosi yang dimiliki remaja laki-laki dan perempuan panti asuhan pada penelitian ini berada pada kategori sedang. Tidak terdapat perbedaan kecerdasan emosi dan resiliensi antara remaja laki-laki dan perempuan panti asuhan, hanya sedikit perbedaan rata-rata. Jenis kelamin bukan menjadi salah satu faktor yang memberikan perbedaan tinggi rendahnya kecerdasan emosi dan resiliensi yang dimiliki individu.

\section{Saran}

Saran bagi peneliti selanjutnya untuk memperhatikan persebaran demografi seperti jenis kelamin, responden laki-laki dan perempuan agar memiliki jumlah yang sama, sehingga mudah untuk mengetahui perbedaan resiliensi dan kecerdasan emosi remaja laki-laki dan perempuan panti asuhan. Selain itu perlu memperhatikan faktor lain yang mungkin dapat melihat perbedaan kecerdasan emosi dan resiliensi remaja laki-laki dan perempuan panti asuhan, seperti faktor orang terdekat remaja. Remaja yang memiliki kemampuan resiliensi rendah dan sedang memiliki potensi untuk ditingkatkan secara optimal. Salah satu cara untuk meningkatkan resiliensi adalah dengan meningkatkan kecerdasan emosi. Dengan meningkatkan kecerdasan emosi, remaja lebih dapat menyesuaikan diri, mengontrol emosi dan mengekspresikan emosi dengan tepat dalam lingkungan panti asuhan.

\section{Kepustakaan}

Albaroroh, R. (2016). Interaksi sosial di Panti Asuhan dalam membentuk tingkah laku anak (Studi di Balai Rehabilitasi Sosial dan Pengasuhan Anak (BRSPA) Sleman Yogyakarta (Program Sarjana). Universitas Islam Negeri Sunan Kalijaga. 
Apriani, F., \& Listiyandini, R. A. (2019). Kecerdasan emosi sebagai prediktor resiliensi psikologis pada remaja di panti asuhan. Jurnal Psikologi Indonesia, 8(2), 325-339. doi:https://doi.org/10.30996/persona.v8ia.2248

Arikunto, S. (2010). Prosedur penelitian: Suatu pendekatan praktek. Jakarta: PT Rineka Cipta.

Ballenger-Browning, K., \& Johnson, D. C. (2010). Key facts on resilience. San Diego CA: Naval Center for Combat \& Operational Stress Control.

Bariyyah, K., \& Latifah, L. (2019). Kecerdasan emosi siswa ditinjau dari jenis kelamin dan jenjang kelas. Jurnal Penelitian Guru Indonesia, 4(2), 68-75.

Bonano, G. A., Galea. S., Bucciarelli, A., \& Vlahov, D. (2007). What predicts psychological resilience after disaster? The role of demographics, resource, and life stress. Journal of Consulting and Clinical Psychological, 75(1), 671-682.

Chong, O. S., Mahamod, Z., \& Yamat, H. (2016). Faktor jantina, kaum, aliran elas dan hubungannya dengan kecerdasan emosi murid dalam mempelajari Bahasa Melayu. Jurnal Pendidikan Bahasa Melayu, 3(1), 12-23.

Connor, K. M., \& Davidson, J. R. (2003). Development of a new resilience scal: the ConnorDavidson resilience scale (CD-RISC). Journal of Depression And Anxiety, 18, 76-82.

Djafar, A., Noviekayati, IGAA., \& Saragih, S. (2018). Perbedaan adversity quotient dan kematangan emosi remaja SMP ditinjau dari jenis kelamin. Jurnal Psikogenesis, 6(1), 61-68.

Eliyawati, R., \& Prasukma, P. (2013). Perbedaan tingkat resiliensi pada remaja dalam keluarga disfungional ditinjau dari jenis kelamin. Jurnal Fenomena, 8(1).

Erdogan, E., Ozdogan, O., \& Erdogan, M. (2015). University students' resilience level: the effect of gendr and faculty. Procedia - Social and Behavioral Sciences, 186, 12621267. doi: $10.1016 /$ j.sbspro.2015.04.047

Fauziya, L. I., \& Daulima, N. H. C. (2017). Hubungan kecerdasan emosi dengan resiliensi penyintas banjir. Jurnal Keperawatan Indonesia, 20(3), 148-157. doi: 10.7454/jki.v20i3.624

Goleman, D. (2000). Emotional intelligence (terjemahan). Jakarta: PT Gramedia Pustaka Utama.

Goleman, D. (2009). Emotional intelligence. Kecerdasan emosional mengapa EI lebih penting daripada IQ (terjemahan). Jakarta: PT Gramedia Pustaka Utama.

Gottman, J., \& DeClaire, J. (1997). Kiat-kiat membesarkan anak yang memiliki kecerdasan emosional. Jakarta: PT Gramedia Pustaka Utama.

Harjanti, D. K. S. (2021). Kesejahteraan psikologis pada remaja panti asuhan ditinjau dari internal locus of control dan spritualitas. Gadjah Mada Journal Of Psychology, 7 (1), 84-98.

Hartati, L., \& Respati, W.S. (2012). Kompetensi interpersonal pada remaja yang tinggal di panti asuhan asrama dan yang tinggal di panti asuhan cottage. Jurnal Psikologi, 10 (2), 79-86.

Haryanti, D., Pamela, E. M., \& Susanti, Y. (2016). Perkembangan mental emosional remaja di panti asuhan. Jurnal Keperawatan Jiwa, 4(2), 97-104.

Hendrayu, V. F., Kinanthi, M. R., \& Brebahama, A. (2017). Resiliensi keluarga pada keluarga yang memiliki kedua orangtua bekerja. Journal of Psychological Research, 3(2), 104115.

Mahardika, A. K. (2017). Perbedaan resiliensi ditinjau dari jenis kelamin pada remaja dengan orang tua yang bercerai (Skripsi, Universitas Negeri Malang, Malang). Retrieved

from 
http://scholar.google.com/scholar?q=related:_JN70eSEiqMJ:scholar.google.com/\&s cioq $=\& h l=i d \& a s \_s d t=0,5 \# d=g s \_q a b s \& u=\% 23 p \% 3 D \_J N 70 e S E i q M J$

Mayer, J. D., Salovey, P., Caruso, D. R., \& Sitarenios, G. (2003). Measuring emotional intelligence with the MSCEIT V2.0. Emotion, 3 (1), 97-105.

Meyers-Levy, J., \& Loken, B. (2015). Revisiting gender differences: What we know and what lies ahead. Journal of Consumer Psychology, 25(1), 129-149.

Mustafa, M. R., \& Hadiyati, F. N. R. (2019). Hubungan antara self disclosure dengan resiliensi pada remaja di Panti Asuhan Darussalam. Jurnal Empati, 8(1), 192-199.

Oktasari, M., \& Wahyudin, H. (2021). Uji konstruk dan pengukuran resiliensi berdasarkan jenis kelamin menggunakan analisis pemodelan Rasch. Jurnal Bimbingan Konseling Islam, 4(1), 42-53.

Putri, M. L., \& Yusri. (2021). Differences in students emotional intelligence based on gender. Jurnal Neo Konseling, 3(1), 97-103.

Rahmawati, B. D., Listiyandini, R. A., \& Rahmatika, R. (2019). Seberapa jauh aku bisa bangkit? Sebuah studi mengenai profil resiliensi psikologis remaja panti asuhan. Jurnal Insight Fakultas Psikologi Universitas Muhammadiyah Jember, 15(2), 232-248. doi: 10.32528/ins.v15i2.1884

Ruswahyuningsih, M. C., \& Afiatin, T. (2015). Resiliensi pada remaja jawa. Gadjah Mada Journal Of Psychology, 1(2), 96-105.

Safari, M. (2019). Analisis perbedaan kecerdasan emosional siswa laki-laki dan perempuan. Seminar Nasional Multidisiplin Ilmu, 2(1), 196-202.

Safari, M., \& Hestaliana, A. (2019). Pengaruh kecerdasan emosional terhadap prestasi belajar pada siswa SMP Inshafuddin berdasarkan perbedaan jenis kelamin. Jurnal Ilmiah Pendidikan Anak (JIPA), 4(6), 1-21.

Sandri, R. (2015). Perilaku bullying pada remaja panti asuhan ditinjau dari kelekatan dengan teman sebaya dan harga diri. Jurnal Psikologi Tabularasa, 10(1), 43-57.

Schutte, N. S., Malouff, J. M., Hall, L. E., Haggerty, D. J., Cooper, J. T., Golden, C. J., \& Dornheim, L. (1998). Development and validation of a measure of emotional intelligence. Personality and Individual Differences, 25(2), 167-177.

Setyowati, A., Hartati, S., \& Sawitri, D. R. (2010). Hubungan antara kecerdasan emosional dengan resiliensi pada siswa penghuni rumah damai. Jurnal Psikologi Undip, 7(1), 67-77.

Shanta, L., \& Gargiulo, L. (2014). A study of the influence of nursing education on development of emotional intelligence. Journal of Professional Nursing, 30(6), 511520.

Papalia, D. E., Old. S. W., \& Feldman, R. D. (2008). Human development. New York: McGraw Hill Companies, Inc.

Sunarti, E., Islamia, I., Rochimah. N., \& Ulfa, M. (2018). Resiliensi remaja: perbedaan berdasarkan wilayah, kemiskinan, jenis kelamin, dan jenis sekolah. Jurnal Ilmu Keluarga dan Konsumen, 11(2), 157-168. doi: http://dx.doi.org/10.24156/jikk.2018.11.2.157

Yuniar, D., \& Darmawati, I. (2017). Dukungan keluarga berhubungan dengan kecerdasan emosional remaja. Jurnal Keperawatan Komprehensif, 3(1), 9-1. 